\title{
Microsurgical Anatomy of Perforated Arteries in the Hypothalamic Area
}

\section{Hipotalamik Alanda Perforan Arterlerin Mikrocerrabi Anatomisi}

\author{
Wei LIU, Zhi-Ming XU, Xian-Min LIU, Lu KONG, Wei-Ning YIN, Guo-Hua WANG \\ Qingdao Municipal Hospital, Department of Neurosurgery, Qingdao, China
}

Corresponding Author: Wei LIU / E-mail: 1wzmcn@163.com

\begin{abstract}
AIM: This study aimed to investigate the microsurgical anatomy of perforating arteries in the hypothalamic area, which are associated with diabetes insipidus.

MATERIAL and METHODS: A total of 20 adult cadaver heads soaked in formalin were infused with red latex through the carotid artery and vertebral artery, and supplementary perfusion was performed after 1 day.

RESULTS: The perforating arteries in the hypothalamic area could be divided into three groups according to their origins, namely, the former, below and outside groups. The former group mainly comprised the perforating arteries near the current communicating arteries. The outside group comprised the perforating arteries from the upper clinoid segment of the internal carotid and posterior communicating arteries. The below group comprised the bottom hypophyseal arteries of the cavernous segment from the internal carotid artery.

CONCLUSION: Vascular injuries that occur during surgery can be minimised by understanding the distribution of the aforementioned vessels. KEYWORDS: Saddle area, Pituitary stalk, Anatomy

öz

AMAÇ: Çalışmanın amacı, diyabetes insipidusla ilişkili olan ve hipotalamik bölgede bulunan perforan arterlerin mikrocerrahi anatomisini incelemekti.

YÖNTEM ve GEREÇLER: Formalin emdirilmiş 20 yetişkin kadavra kafasına karotid arter ve vertebral arter içinden kırmızı lateks infüzyonu yapıldı ve bir gün sonra ek perfüzyon uygulandı.

BULGULAR: Hipotalamik bölgedeki perforan arterler, kökenlerine göre önceki, aşağıdaki ve dışarıdaki gruplar olarak üç gruba ayrılmaktaydı. Önceki grupta temel olarak mevcut komünikan arterlerin yakınındaki perforan arterler vardı. Dışarıdaki grup posterior komünikan arterler ve internal karotidin üst klinoid segmentinden perforan arterleri içeriyordu. Aşağıdaki grup internal karotid arterin kavernöz segmentinin alt hipofizyal arterlerini içeriyordu.
\end{abstract}

SONUÇ: Cerrahi sırasında oluşan vasküler yaralanmalar adı geçen damarların dağılımının anlaşılmasıyla minimuma indirilebilir.

ANAHTAR SÖZCÜKLER: Sella bölgesi, Hipofiz sapı, Anatomi

\section{INTRODUCTION}

The saddle area and hypothalamic region are predilection sites for tumours and vascular lesions. The microsurgical anatomy of the nerves and blood vessels for this region should be mastered whether the surgery is performed through the wing points, under the forehead or the nose to prevent serious complications $(7,9,15)$. Diabetes insipidus is among the surgical complications that are difficult to manage. We studied the relevant anatomy to provide a theoretical basis for preventing the occurrence of diabetes insipidus during and after surgery. This issue was first reported by Rhoton in 1977 (14), followed by Krisht, Vutskits and Reisth et al., who provided a detailed description of the blood vessels in the region (10, $13,22)$. The present study focuses on human subjects in China. The hypothalamic area includes several structures, such as the anterior hypothalamus, pituitary stalk and pituitary. These structures are commonly affected by serious complications, such as postoperative diabetes insipidus and electrolyte imbalance. Neural structures in the hypothalamic area include the following: the supraoptic nucleus and paraventricular nucleus anterior to the hypothalamus; pituitary stalk; and the neurohypophysis, which secretes and releases vasopressin (AVP), brain natriuretic peptide (BNP) and atrial natriuretic peptide (ANP). AVP, BNP and ANP are important neuropeptides that regulate water and electrolyte imbalances. Any disturbance in the blood supply of the hypothalamus, pituitary stalk and neurohypophysis results in central diabetes insipidus and electrolyte imbalance after surgery $(1,11)$. We examined 20 adult brain specimens to understand the microsurgical anatomy of blood supply to the hypothalamus, pituitary stalk and neurohypophysis. Results can be used as a basis for surgery on this anatomical region to minimise the occurrence of water and sodium metabolic disorders from post-operative vascular injury. 


\section{MATERIAL and METHODS}

\section{Subjects}

A total of 20 adult human heads were obtained from formalinfixed corpses in the Dissection Laboratory of the Medical College of Qingdao University, Shandong, China.

\section{Microsurgical Anatomy}

Red latex was perfused through the internal carotid artery (ICA), and the skull cap was removed after solidification. The perforating arteries from the clinoid segment of the ICA and Circle of Willis distributed in the bottom of the third ventricle, pituitary stalk and neurohypophysis were dissected under a $6 \times$ to $16 \times$ surgical microscope (Germany Leica M520) with auxiliary microsurgical instruments. The origin, course and distribution of these perforating arteries were determined.

\section{Data Measurement}

The diameter and length of the blood vessels were measured using a micrometer caliper with an accuracy of $0.02 \mathrm{~mm}$.

\section{Statistical Analysis}

The obtained data were analysed using a two-sample $t$ test. The measured values are presented as $\bar{\chi} \pm s$, and differences with $p>0.05$ were considered significant.

\section{RESULTS}

\section{General Situation}

The supraoptic and paraventricular nuclei of the hypothalamus occur in pairs in the third ventricle of the anterolateral wall, and these nuclei synthesise and transport AVP to the posterior pituitary through the stalk for storage and release in this area (1). The perforating arteries were divided into three parts based on the respective origins of the vessels in the zone, namely, the hypothalamus, pituitary stalk and neurohypophysis: the former group comprised perforating arteries from the communicating arteries anterior to the front of the third ventricle; the outside group comprised perforating arteries that originate from the posterior communicating artery ( $\mathrm{PCOA}$, the superior hypophyseal artery); and the below group comprised perforating arteries that supply the neurohypophysis from the inferior hypophyseal arteries (Figure 1).

\section{Former Group}

The former group comprised the perforating arteries close to the communicating arteries located anterior to the third ventricle. The perforating branches of the hypothalamic arteries originate from the anterior communicating artery $(A C O A)$. The perforating branches start from the anterior cerebral artery (ACA) and $A C o A$, and terminate in the entire front wall of the third ventricle and adjacent hypothalamus. Most of the hypothalamic perforating branches comprised one to six arteries (average of 3.2 arteries) from the posterior or posteroinferior wall of the ACA and ACoA. The vessel diameter was $0.18 \pm 0.11 \mathrm{~mm}$ (ranging from $0.1 \mathrm{~mm}$ to
$0.3 \mathrm{~mm}$ ). A total of $12 \%$ of the arteries started from one side of the ACoA to supply the anterior wall of both sides of the third ventricle. The hypothalamic branch corresponded to the posterior branch of the callosum, and these branches jointly supplied the anterior hypothalamus. The recurrent artery of Heubner, a unique artery with a diameter of $1.2 \pm 0.9 \mathrm{~mm}$ (ranging from $0.2 \mathrm{~mm}$ to $0.8 \mathrm{~mm}$ ), originated from the ACA. The recurrent arteries that originated from the $A 2$ segment, A1 segment and ACoA level accounted for $76.8 \%, 14 \%$ and $9.2 \%$ of the arteries present, respectively. The arteries only visible on one side accounted for $73 \%$ of the total number of arteries, whereas those present on two sides accounted for $8 \%$. The average number of branches for the returning artery was $4.2 \pm 3$ (ranging from two to seven branches) (Figure $2 A, B)$. The returning artery seldom supplied the anterior hypothalamus.

\section{Outside Group}

The outside group comprised the perforating arteries that originated from the outside of the third ventricles, pituitary stalk and two blood supply regions (1). The blood supply of the third ventricle was mainly from the perforating arteries that originated from the lower part of the PCoA. Up to 17 of the 20 head specimens had a PCoA from the ICA, and three specimens had hypoplastic PCoA in one side and a naive PCoA in the other side. PCoA formed the external Circle of

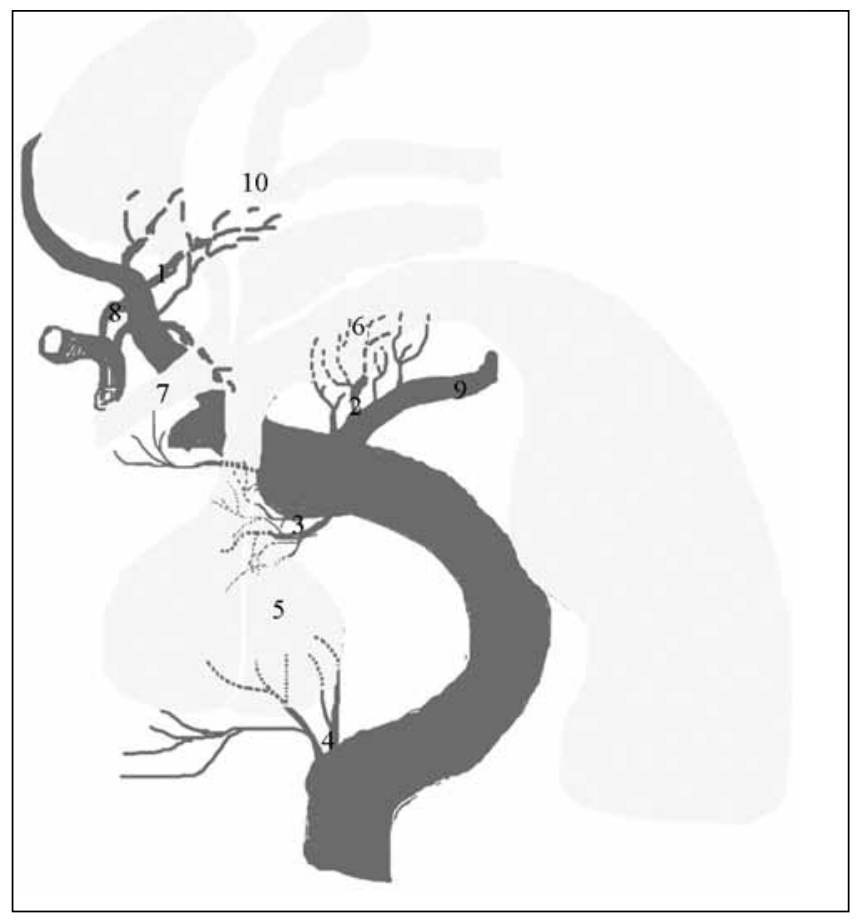

Figure 1: Schematic of blood supply for the hypothalamic region. 1. Perforating branches of the anterior communicating artery; 2. Perforating branches of the posterior communicating artery; 3. Upper hypophyseal artery; 4. Inferior hypophyseal artery; 5. The posterior lobe of pituitary; 6 . Mammillary bodies; 7. Chiasm; 8. A anterior communicating artery; 9 . Posterior communicating artery; 10 . The anterior wall of the third ventricle. 
Willis. A total of 4 to 11 branches (average of 6.4 branches) were distributed along the path of the PCoA in this group. The diameter ranged from $0.3 \mathrm{~mm}$ to $2.1 \mathrm{~mm}$, with an average of $1.7 \mathrm{~mm}$. A total of $73 \%$ of the PCoA branches terminated between the mammillary body and optic tract (premammillary area); thus, the artery is called the premammillary artery. A set of small central arteries that originated from the PCOA and perforating branches near the PCoA entered the bottom of the third ventricle of the brain between the foot and optic chiasm to reach the thalamus, hypothalamus, base of the thalamus and internal capsule (Figure 2C). The perforating arteries in the distal segment of the PCOA mainly supplied the hypothalamic core (2). The superior hypophyseal artery, which supplied the pituitary stalk, originated from the upper segment of the ICA. Each of the 40 sides in this group had one to four hypophyseal arteries (average of $1.3 \pm 0.77$ branches) and a diameter of $0.38 \pm 0.11 \mathrm{~mm}$. The arteries originated from the lower interior wall of the ophthalmic artery segment of the ICA clinoid segment (78\%), inner wall (16\%) and lower wall (6\%). Most of the specimens had one hypophyseal artery.
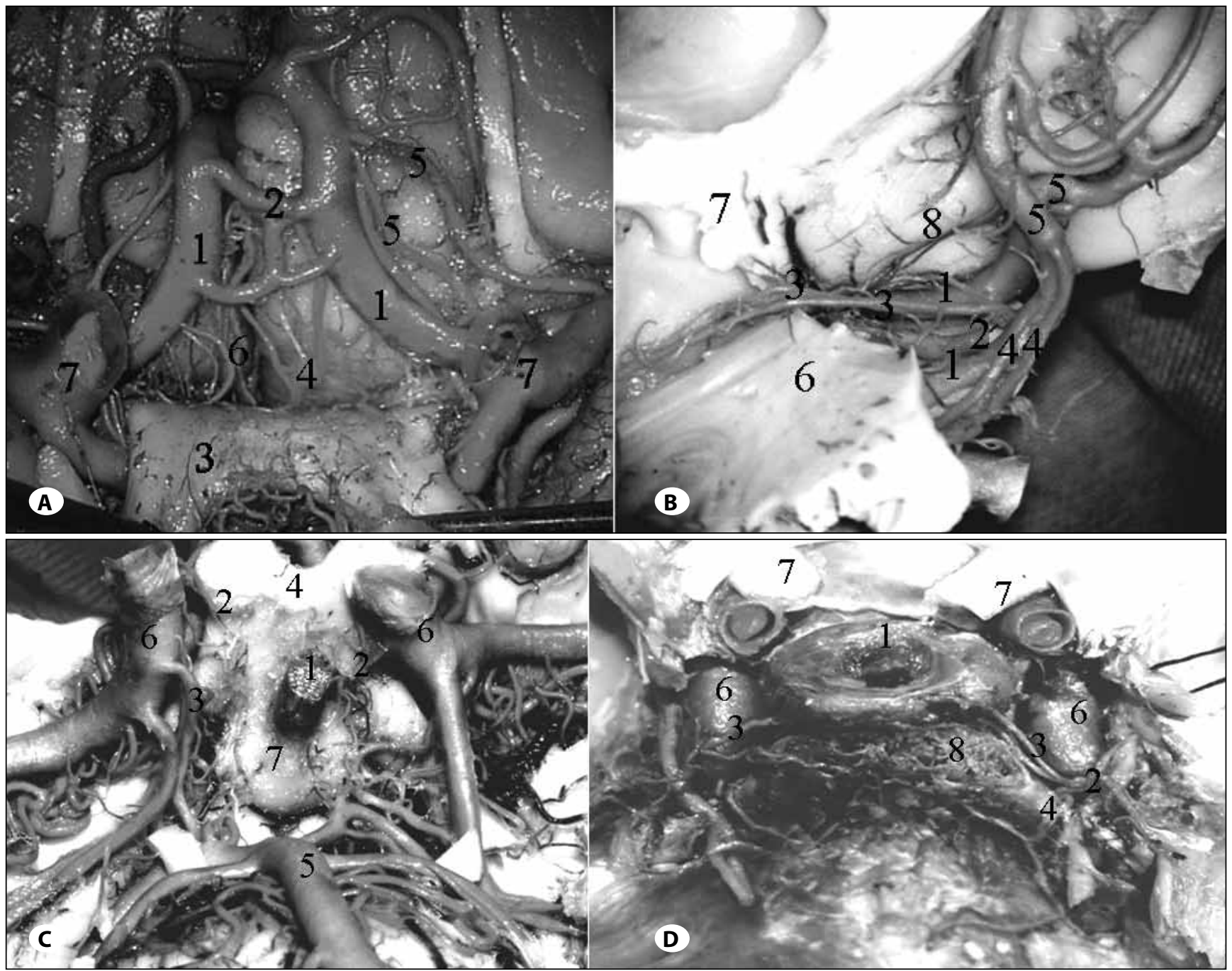

Figure 2: Perforating arteries walk of hypothalamus region in different angles. A) Anterior communicating artery and underside view of the branches. 1 . A1 segment of the left and right for anterior cerebral artery; 2 . Anterior communicating artery; 3 . Retracted down optic chiasm; 4. Perforating branches of the optic chiasm from the anterior communicating artery; 5 . Two Heubner recurrent artery from the A2 segment of anterior cerebral artery; 6 . Hypothalamic perforating branches from the anterior communicating artery; 7. Internal carotid artery. B) Anterior communicating artery and the lateral view of the branches. 1 . A1 segment of the left and right for anterior cerebral artery; 2 . Anterior communicating artery; 3. Hypothalamic perforating branches from the anterior communicating artery; 4. Two Heubner recurrent artery from the A2 segment of anterior cerebral artery; 5 . A2 segment of anterior cerebral artery; 6 . Anterior wall of the third ventricle; 7. Anterior commisure; 8. Gyrus rectus. C) Underside view of hypophyseal artery. 1. Pituitary stalk; 2. Upper hypophyseal artery; 3. Posterior communicating artery and the supplied perforating branches in the lower outside wall of the third ventricular; 4. Chiasm; 5. Basilar artery; 6. Internal carotid artery; 7. Mammillary bodies. D) Upper view of pituitary artery. 1. Pituitary; 2. Meninges pituitary trunk; 3. Inferior hypophyseal artery; 4. Dorsal meningeal artery; 5 . Tentorial meningeal artery; 6. Internal carotid artery; 7. Optic nerve; 8 . Dorsum sellae. 
Several other arteries accompanied the branches of the optic chiasm and optic nerve, distributed into the periphery of the pituitary stalk and funnel and formed the funnel-like peripheral arterial ring with the corresponding arteries. Radiating branches were distributed in the pituitary stalk, anterior lobe of the pituitary funnel and hypothalamic funnel area (Figure 2C).

\section{Below Group}

The below group originated from the outside of the third ventricle and pituitary stalk. The emergence of the inferior hypophyseal arteries in this group was $100 \%$, among which $67.5 \%$ radiated from the meningeal pituitary branches in the bend after the ICA cavernous segment, 20\% jointly radiated with the tentorial meningeal artery and dorsal artery of meninges and $12.5 \%$ radiated as a single branch. The average diameter of the inferior hypophyseal artery was $0.66 \pm 0.19 \mathrm{~mm}$ (ranging from $0.30 \mathrm{~mm}$ to $1.02 \mathrm{~mm}$ ). The main trunk, which had an average length of $7.99 \pm 3.94 \mathrm{~mm}$ (ranging from $2.20 \mathrm{~mm}$ to $15.71 \mathrm{~mm}$ ), entered the anteriomedialis, bypassing the rear inner wall of the ascending portion for the ICA cavernous segment, and into the intermediate lobes between the front and rear lobes at one-third of the junction. A total of $90 \%$ of the arteries entered the ascending and descending branches, thereby forming the artery rings with the corresponding arteries and superior hypophyseal artery with the same name above and below the pituitary gland to constitute the pituitary-portal system. This system was the major supply of the posterior pituitary and pituitary stalk (Figure 2D).

\section{DISCUSSION}

Diabetes insipidus after surgery involving the saddle area can occur regardless of the choice of surgical approach, but this disease is directly related to vascular injury caused by the surgical approach. Direct damage to the hypothalamuspituitary stalk-posterior lobes of the pituitary should be avoided. The hypothalamus (mainly the supraoptic and paraventricular nuclei)-pituitary stalk-neural pituitary axis is the structural basis for AVP synthesis, transport and release. Any damage to these structures can cause central diabetes insipidus, and injury to vascular factors account for a large proportion of disease occurrence $(18,25)$. During operation, trauma and general ailments are caused by spasm of the vessels supplying the hypothalamus-pituitary stalkposterior lobes axis. Damage in the corresponding area may result in ischemia and infarction. Injury may affect the release of antidiuretic hormone AVP, thereby resulting in diabetes insipidus. Anatomical analysis of the blood supply to hypothalamus, pituitary stalk and neurohypophysis revealed that the blood vessels in this area could be classified into three groups: (1) the former group comprised perforating arteries near the communicating artery; (2) the outside group comprised perforating arteries from the superior hypophyseal artery and $\mathrm{PCoA}$; and (3) the below group comprised the perforating arteries from the inferior pituitary artery of the cavernous segment for the ICA.
The former group: During clipping of the ACoA aneurysm, many neurosurgeons ignore the penetrating vessels radiating from the ACoA. Yasargil et al. named these vessels "hypothalamic arteries," which perfuse the preoptic area of the funnel, optic chiasma, lower part of the callosum and hypothalamus (24). Crowell and Morawetz et al. reported that perforating arteries from the ACA are common (3). However, the number, diameter, starting location, area and blood supply of these vessels, especially their classification and nomenclature, remain controversial. We support the view of Serizawa (17), who observed that these perforating arteries are divided into three groups according to the blood supply area: the inferior branch of the callosum; hypothalamic branch and chiasm branches. The diameter, number and starting position of these vessels vary. These perforating arteries may limit surgery when performed via the interhemispheric approach, in which the hypothalamus branch mainly supplies the front of the third ventricle. Occlusion of these arteries during surgery causes ischemia of the supraoptic nucleus and paraventricular nucleus in the anterior wall of the third ventricle, thereby resulting in blood supply disorders and central diabetes insipidus. The lower branch of the callosum is one of the thickest among the arteries that terminate at both sides of the lower part of the callosum and anterior hypothalamus. Occasionally, the lower branch of the callosum becomes a major blood vessel of the anterior hypothalamus. These perforating branches are easily damaged during surgical clipping in the direction of the rear or back at the top of the ACoA aneurysm. To avoid damaging these vessels during surgery, the following precautions are necessary: 1) remember that the hypothalamic branch can start from one side of the $A C O A$ and terminate in the contralateral anterior hypothalamus; 2 ) the lower branch of the callosum occasionally supplies the anterior hypothalamus, even bilaterally, indicating that these perforating arteries should not be ignored during surgery; and 3) all ACoAs, regardless of their vessel diameters, can have perforating branches. Heubner's arteries originating from the ACA often perfuse the supraoptic and paraventricular nuclei (20).

The perforating arteries from the lower part of the hypothalamus are mainly from the PCOA and anterior artery of the mammillary bodies (19). In specimens of the embryonic PCoA, the appearance of the mammillary artery indicates the diameter of the artery. Agenesis of one side of the PCoA resulted in the perfusion of the perforating branches from the ICA and vascular cerebral artery into the hypothalamus and mammillary region. Hypophyseal arteries belong to a small group originating from the lateral wall of the ophthalmic part of the ICA clinoid segment and medial wall, which reportedly contains two to five branches $(2,4)$ (one to four branches in the present study). The hypophyseal artery went in the direction of the posterosuperior space and inside the space in multiple directions, branching in the subarachnoid space under the optic chiasma and pituitary stalk and joining the contralateral arteries with the same name to form a collar-like clump around the upper segment of the 
pituitary stalk. This collar-like clump was designated by Gibo et al. as the funnel peripheral arterial ring (5). The ascending aorta and descending artery originated from the ring. The ascending aorta perfused the gray nodules, inner uplift area and posterior of the optic nerve and chiasm, whereas the descending artery branched along the pituitary stalk towards the pituitary stalk and anterior lobes of the pituitary gland. Using the Yasargil pterional approach during microsurgery for pituitary adenoma and craniopharyngioma by the part I interspace, a small ICA clinoid segment under the contralateral optic nerve and a set of upper hypophyseal arteries from the lower inner wall were visible because of $15^{\circ}$ to $20^{\circ}$ rotation of the head to the opposite side. The set of arteries perfused the saddle compartment or tumefied tumor capsule, and were distributed posterosuperior to the optic nerve, optic chiasma and pituitary stalk. This part should be carefully stripped and protected, and coagulation and cutting should remain close to the tumor capsule to avoid postoperative ischemia and oedema of the optic nerve, pituitary stalk and hypothalamus. Ischemia and oedema may be caused by bleeding or nerve trunk damage, which could lead to changes in consciousness, visual disturbance, diabetes insipidus, electrolyte imbalance and other serious complications. This set of small arteries perfused the optic chiasma-funnel and the gray nodulesmammillary regions. Previous studies suggested that postoperative visual acuity deterioration in some patients is related to hypophyseal artery injury (23). The deterioration of the visual acuity of patients was mostly associated with different degrees of central diabetes insipidus, which was possibly related to blood supply disorders of the hypophyseal artery. The deficiency in the reasonable use of anatomical spaces and improper surgery could induce vasospasms because of excessive stretching of these perforating arteries and prolonged exposure. Ischemia disrupts AVP synthesis in the hypothalamic paraventricular nucleus and supraoptic nucleus.

The hypophyseal artery is an important branch of the ICA cavernous segment that occurs in $80 \%$ to $100 \%$ of people (8). This artery occurred in $100 \%$ of the samples in the current study. In most cases, the arteries originate from the meningeal pituitary trunk after the bend of ICA. Some arteries directly start after the ascending part or bend of ICA, and pass through the intermedial space of the cavernous sinus to the forward and inside line. Subsequently, these arteries branch and ascend to the middle and lower parts up to onethird of the junction in the middle area located between the before and after pituitary outside lobes. The arteries join the contralateral and upper hypophyseal arteries at the upper and bottom parts of the pituitary gland into the arterial ring. Three groups of branches start from the arterial ring: (1) the group that goes directly into the posterior lobe of the branch; (2) the group that goes into the pituitary cyst branch; and (3) the group that goes into the main trunk of the artery among the lobes, which constitute the pituitary portal system. The selective injection of contrast performed by Leclercq showed that the arterial blood initially perfuses the artery under the pituitary and subsequently supplies the arteries of the posterior pituitary, pituitary stalk and parts of the hypophyseal area around the pituitary stalk (21). The posterior hypophyseal artery is considered the most important artery supplying the neurohypophysis (16). During microsurgery of the saddle and cavernous sinus area, the pituitary artery must be protected to prevent complications, such as water and electrolyte disorders, which arise because of the injury from ischemia of the posterior lobe of the pituitary, especially during the transsphenoidal resection of pituitary adenomas. Excessive coagulation of the pituitary capsule should be avoided to prevent severe diabetes insipidus in the bilateral pituitary artery. Severe diabetes insipidus reportedly occurs when one side of the meningeal pituitary trunk is blocked (6, 12). Thus, the meningeal pituitary trunk is the most important blood vessel supplying the neurohypophysis. We believe that permanent diabetes insipidus that occurs in patients after transsphenoidal surgery results from the overuse injury of the posterior lobes of the posterior pituitary in the meningeal pituitary trunk. This type of injury is caused by coagulation, which is related to ischemic necrosis of the pituitary stalk.

\section{REFERENCES}

1. Cappabianca P, Cavallo LM, Colao A, de Divitiis E: Surgical complications associated with the endoscopic endonasal transsphenoidal approach for pituitary adenomas. J Neurosurg 97(2): 293-298, 2002

2. Ciric I, Ragin A, Baumgartner C, Pierce D: Complications of transsphenoidal surgery: results of a national surgery, review of the literature, an personal experience. Neurosurg 40(2): 225-237, 1997

3. Crowell RM, Morawetz RB: The anterior communicating artery has significant branches. Stroke 8(2):272-273,1977

4. Feng YG, Xu ZM, Wang WM: The microanatomy of pituitary gland and the applied research in surgery of the sellar region. Zhong Hua Shen Jing Yi Xue Za Zhi 3: 430-432, 2004

5. Gibo H, Hokama M, Kyoshima K, Kobayashi S: Arteries to the pituitary. Nihon Rinsho 51(10):2550-2554, 1993

6. Hensen J, Seufferlein T, Oelkers W: Atherosclerosis, aortic stenosis and sudden onset central diabetes insipidus. Exp Clin Endocrinol Diabetes 105(4): 227-233, 1997

7. Isolan GR, de Aguiar PH, Laws ER, Strapasson AC, Piltcher $O$ : The implications of microsurgical anatomy for surgical approaches to the sellar region. Pituitary 12(4): 360-367, 2009

8. Ju XH, Jiang JY, Wang JP: The applied anatomy of the artery of pituitary gland. Zhong Guo Lin Chuang Ji Pou Xue Za Zhi 20: 33-34, 2002

9. Kawamata T, Kubo O, Kamikawa S, Hori T: Ectopic clival craniopharyngioma. Acta Neurochirurgica 144(11): 12211224, 2002

10. Krisht AF, Barrow DL, Barnett DW, Bonner GD, Shengalaia G: The microsurgical anatomy of the superior hypophyseal artery. Neurosurgery 35(5): 899-903, 1994 
11. Luo S, Pan J, Qi ST, Fang LX, Fan J, Liu BG: Analysis of the factors contributing to diabetes insipidus after surgeries for craniopharyngiomas. Nan Fang Yi Ke Da Xue Xue Bao 29(3): 544-547, 2009

12. Phatouros CC, Higashida RT, Malek AM, Smith WS, Dowd CF, Halbach VV: Embolization of the Meningohypophyseal Trunk as a Cause of Diabetes Insipidus. Am J Neuroradiol 20(6): 1115-1118, 1999

13. Reisch R, Vutskits L, Patonay L, Fries G: The meningohypophyseal trunk and its blood supply to different intracranial structures. An anatomical study. Minim Invasive Neurosurg 39(3): 78-81, 1996

14. Rhoton AL Jr, Harris FS, Renn WH: Microsurgical anatomy of the sellar region and cavernous sinus. Clin Neurosurg 24: 5485,1977

15. Rhoton AL Jr: The sellar region. Neurosurgery 51 Suppl 4: S335-374, 2002

16. Riche H, Jaboulay JM, Chiara Y, Peloux A: Posteroperative complications of transsphenoidal surgery. Minerva Anestesiol 58 Suppl 1: 71-72, 1992

17. Serizawa T, Saeki N, Fukuda K, Yamaura A: Microsurgical anatomy of the anterior communicating artery and its perforating arteries important for interhemispheric translamina terminalis approach: analysis based on cadaver brains. No Shinkei Geka. 1994 May;22(5):447-54.

18. Shi X, Huang W, Wang Z: Preservation of the hypothalamic structures in the total resection of craniopharyngioma. Chin Med Sci J 16(4): 218-222, 2001
19. Shi X, Rhoton AL Jr, Huang W: Microsurgical anatomy of the perforating arteries on the third ventricular floor. Zhonghua Yi Xue Za Zhi 82(5): 304-307, 2002

20. Toru S, Naokatsu S, Akira Y: Microsurgical anatomy and clinical significance of the Anterior communicating artery and its perforating branches. Neurosurgery 40(6): 1211-1218, 1997

21 Tungria A, Kumar V, Garg P, Jaiswal AK: Giant, thrombosed, sellar-suprasellar internal carotid artery aneurysm with persistent, primitive trigeminal artery causing hypopituitarism. Acta Neurochir (wien) 153(5): 1129-1133, 2011

22. Vutskits L, Reisch R, Patonay L, Fries G: The "rete mirabile" of the clivus and the dorsum sellae. A microanatomical study. Minim Invasive Neurosurg 39(4): 138-140, 1996

23. Wu JD, Hui GZ, Xia CL: The microsurgical anatomy of the superior hypophyseal artery. Zhong Hua Shen Jing Wai Ke Za Zhi 16: 146-148, 2004

24. Yasargil MG, Kasdaglis K, Jain KK, Weber HP: Anatomical observations of the subarachnoid cisterns of the brain during surgery. J Neurosurg 44(3):298-302, 1976

25. Zada G, Cavallo LM, Esposito F, Femandez-Jimenez JC: Transsphenoidal surgery in patients with acromegaly: Operative strategies for overcoming technically challenging anatomical variations. Neurosurg Focus 29(4): E8, 2010 